Rhode Island College

Digital Commons @ RIC

\title{
Symptom Triggered Therapy versus Fixed-Dosed Scheduling for Alcohol Withdrawal: A Systematic Review
}

Amanda Saucedo

Follow this and additional works at: https://digitalcommons.ric.edu/etd

Part of the Nursing Commons

\section{Recommended Citation}

Saucedo, Amanda, "Symptom Triggered Therapy versus Fixed-Dosed Scheduling for Alcohol Withdrawal: A Systematic Review" (2021). Master's Theses, Dissertations, Graduate Research and Major Papers Overview. 389.

https://digitalcommons.ric.edu/etd/389

This Major Paper is brought to you for free and open access by the Master's Theses, Dissertations, Graduate Research and Major Papers at Digital Commons @ RIC. It has been accepted for inclusion in Master's Theses, Dissertations, Graduate Research and Major Papers Overview by an authorized administrator of Digital Commons @ RIC. For more information, please contact digitalcommons@ric.edu. 
A Major Paper Presented

by

Amanda Saucedo

A Major Paper Submitted in Partial Fulfillment

of the Requirements for the Degree of

Master of Science in Nursing

In

The School of Nursing

Rhode Island College

2021 


\begin{abstract}
Alcohol Use Disorder (AUD) is a significant health problem that is seen widely in all hospitals and in the community. Individuals who have AUD and cease to consume alcohol develop Alcohol Withdrawal Syndrome (AWS). Alcohol Withdrawal Syndrome can either be treated on an inpatient or outpatient basis. Three different pharmacological regimens for treating AWS with medications exist. The three regimens include fixeddosing, symptom-triggered, and loading dose regimens (Sachdeva et al., 2015). As Acute Care Nurse Practitioners (APRNs), AWS will be a common diagnosis treated. Advanced Practice Registered Nurses (APRNs) must be aware of the different treatment modalities and the best evidence-based regimens for treating AWS. The purpose of this project is to conduct a systematic review to determine if the use of symptom-triggered dosing compared to fixed-schedule dosing of benzodiazepines for the treatment of AWS decreases total dosage of benzodiazepines administered during the course of treatment.
\end{abstract}




\section{Table of Contents}

Background/Statement of the Problem .................................................................. 1

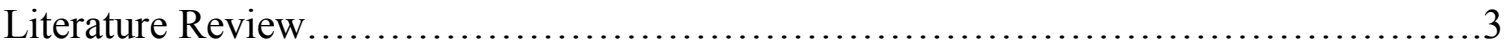

Theoretical Framework........................................................... 14

Methods...................................................................... 17

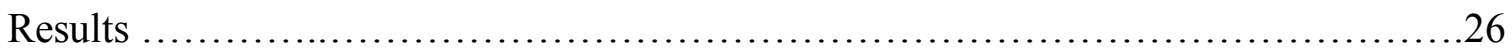

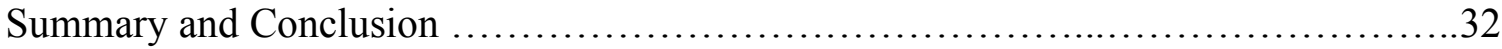

Recommendations and Implications for Advanced Nursing Practice ...................34

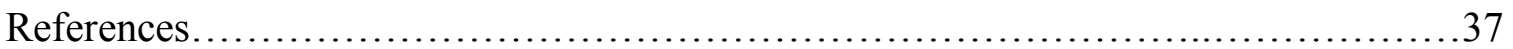

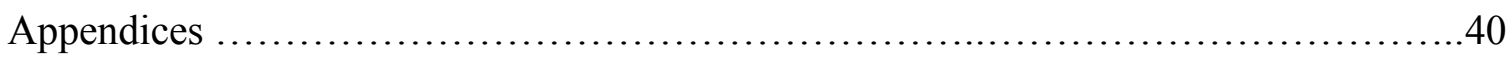


Symptom Triggered Therapy Versus Fixed-Dosed Scheduling for Alcohol Withdrawal: A Systematic Review

\section{Background/Statement of the Problem}

Alcohol Use Disorder (AUD) is a significant health problem that is seen widely in all hospitals and in the community. Alcohol Use Disorder is defined as "a chronic relapsing brain disease characterized by compulsive alcohol use, loss of control over alcohol intake, and a negative emotional state when not using” (National Institute on Alcohol Abuse and Alcoholism [NIAAA], 2019). The over consumption of alcohol can also be associated with other comorbidities making it difficult to treat. According to the NIAAA, about 16 million Americans over the age of 18 have AUD, an increase from 15 million in 2015.

Individuals who have AUD and cease to consume alcohol develop Alcohol Withdrawal Syndrome (AWS). Alcohol Withdrawal Syndrome is characterized by a cluster of symptoms that can range from mild to severe from the cessation or reduction in excessive alcohol consumption (Sachdeva et al., 2015). Proper treatment with medications is indicated in all cases of AWS, from mild to severe (Sachdeva et al., 2015). The preferred pharmacological treatment method for AWS is with benzodiazepines (Sachdeva et al., 2015). The goal of AWS treatment with benzodiazepines is to reach a calm but awake and oriented state (Sachdeva et al., 2015). According to Sachdeva (2015), without the prompt and adequate amount of benzodiazepine administration, AWS can be fatal.

Alcohol Withdrawal Syndrome can either be treated on an inpatient or outpatient basis. Patients who are at low risk of developing severe withdrawal symptoms can be 
treated as outpatients (Sachdeva et al., 2015). Patients who develop moderate or severe AWS and have other medical-comorbidities and multiple failed attempts at staying sober need close inpatient monitoring (Sachdeva et al., 2015). Three different pharmacological regimens for treating AWS with medications exist. The three regimens include fixeddosing, symptom-triggered, and loading dose regimens (Sachdeva et al., 2015). With fixed-schedule dosing (FSD), benzodiazepines are administered at scheduled times. During FSD, benzodiazepines are tapered slowly, and they are administered regardless of whether a patient is experiencing symptoms or not (Skinner, 2014). In symptom-triggered therapy (STT), benzodiazepines are administered in response to the development of withdrawal symptoms that are monitored using the Clinical Institute Withdrawal Scale (CIWA) (Skinner, 2014). With this therapy, patients only receive medication when they are exhibiting symptoms. Loading dose regimens (LDRs) use long-acting benzodiazepines in large doses to reduce the risk of complications (Sachdeva et al., 2015).

As Acute Care Nurse Practitioners (APRNs), AWS will be a common diagnosis treated. According to Sachdeva et al. (2015), inpatient treatment of AWS results in a higher cost for inpatient treatment of AWS. Advanced Practice Registered Nurses (APRNs) must be aware of the different treatment modalities and the best evidence-based regimens for treating AWS.

The purpose of this project is to conduct a systematic review to determine if the use of symptom-triggered dosing compared to fixed-schedule dosing of benzodiazepines for the treatment of AWS decreases total dosage of benzodiazepines administered during the course of treatment. 


\section{Literature Review}

A literature review was conducted using the databases CINAHL and Google Scholar. Multiple search terms including alcohol withdrawal, alcohol abuse treatment, symptom-triggered therapy, and fixed-dosed therapy were used in the search. Only articles in English language and with full-texts were used in the searches. Inclusion criteria were comprised of articles that included inpatients, outpatients, and adults (ages 18 and over). Exclusion criteria included pediatrics (younger than 18 years old). Articles from the years 2010-2020 were searched.

\section{Alcohol Use Disorder}

Alcohol Use Disorder (AUD) is a significant health problem that is seen widely in all hospitals and in the community. Alcohol Use Disorder is defined as "a chronic relapsing brain disease characterized by compulsive alcohol use, loss of control over alcohol intake, and a negative emotional state when not using" (National Institute on Alcohol Abuse and Alcoholism [NIAAA], 2019). The over consumption of alcohol can also be associated with other comorbidities making it difficult to treat. According to the NIAAA, about 16 million Americans over the age of 18 have AUD, an increase from 15 million in 2015. Individuals who have AUD and cease to consume alcohol develop Alcohol Withdrawal Syndrome (AWS).

\section{Alcohol Withdrawal Syndrome}

Alcohol is a central nervous system (CNS) depressant that acts on two major pathways, the inhibitory y-aminobutyric acid (GABA) and excitatory N-methyl-Daspartate (NMDA glutamate) pathways. Glutamate and GABA are the major neurotransmitters in the brain. Inhibitory GABA and excitatory glutamate work together 
to maintain the brain's overall level of excitation. GABA's function is to decrease the activity of the neurons to which it binds (Perry, 2014). GABA receptors are channel receptors in the brain to which GABA binds. When GABA binds to these receptors, the receptors change shape to allow negatively charged chloride ions to enter the neuron, making the neuron more negative and less likely to respond to stimuli, reducing its excitability (Perry, 2014). This property is what makes GABA an inhibitory neurotransmitter.

Glutamate is another chemical messenger and neurotransmitter found in the brain. When glutamate binds to an NMDA receptor, positive sodium and calcium ions flow into the neuron, causing the neuron to be more positive and more likely to respond to stimuli, thus being the excitatory pathway (Perry, 2014). With alcohol consumption, the activity of GABA at the receptors increases, causing negative chloride ions to influx into the neuron and leading to inhibitory effects (Perry, 2014). Simultaneously, alcohol consumption blocks the excitatory action of glutamate at the NMDA receptors, causing sedative and depressant effects (Perry, 2014). With prolonged alcohol consumption, GABA receptors are down-regulated, and NMDA receptors are up-regulated to maintain homeostasis (Perry, 2014). When an individual abruptly discontinues the consumption of alcohol, an excitatory state develops because of these changes (Perry, 2014). This excitatory state includes tremors, agitation, anxiety, restlessness, diaphoresis, hallucinations, and headaches. This excitatory state is what causes the signs and symptoms of alcohol withdrawal.

Alcohol Withdrawal Syndrome (AWS) is a very common diagnosis seen in acute care facilities (Perry, 2014). Alcohol withdrawal syndrome (AWS) is diagnosed through 
a physical exam and history (Sachdeva et al., 2015). During the physical exam, the provider would note tachycardia, hypertension, tachypnea, diaphoresis, agitation, vomiting, and, at times, fever (Perry, 2014). Neurological symptoms of AWS include visual/auditory/tactile hallucinations and seizures. Laboratory work is not necessary for diagnosis, a provider may obtain a blood alcohol level (BAL) to know how much alcohol a person has consumed. When diagnosing the syndrome, the provider must obtain a very detailed history regarding the amount and frequency of alcohol intake the patient has consumed (Sachdeva et al., 2015). For the diagnosis of AWS to be made, the following conditions need to be in met: clear evidence of recent cessation or reduction of alcohol consumption; symptoms of alcohol withdrawal cannot be due to other diagnoses; and the symptoms of AWS must cause a decline in functional status and other important areas of functioning such as inability to perform ADL's, inability to ambulate with a steady gait, and inability to concentrate (Sachdeva et al., 2015). The Diagnostic and Statistical Manual of Mental Disorders (DSM-V) outlines the same diagnostic criteria for AWS as Sachdeva et al. (2015) presents. The DSM-V states a cessation or reduction in alcohol consumption must be present. For the DSM-V diagnostic criteria, patients must also demonstrate two of the following symptoms: sweating, tachycardia, increased hand tremor, insomnia, nausea or vomiting, visual/auditory/tactile hallucinations, and seizures (Perry, 2014).

According to Adis Medical Writers (2014), 20\% of hospitalized patients abuse alcohol or are alcohol dependent and, of these, $8 \%$ will develop symptoms of AWS while hospitalized. Individuals who abruptly stop drinking alcohol may develop AWS. According to Murdoch et al. (2014), the onset of symptoms of AWS can occur after 48 
hours and up to 72 hours from the last alcoholic beverage consumed. The symptoms of AWS include tremors, sweating, auditory hallucinations, visual hallucinations, tremors, insomnia, nausea, vomiting, tactile disturbances, agitation, anxiety, and seizures (Murdoch et al., 2014). Alcohol withdrawal seizures can occur within the first 48 hours after the cessation of alcohol (Perry, 2014). Delirium tremors (DTs) are the most lifethreatening complications of AWS and occur in 5\% of hospitalized patients (Perry, 2014). Delirium tremor symptoms include severe agitation, tremors, disorientation, hallucinations, and increased tachycardia, hypertension, and tachypnea (Perry, 2014). Delirium tremor symptoms can begin three to five days after the last drink and can persist for up to seven days (Perry, 2014).

\section{Morbidity and Mortality from AWS}

Larson et al. (2012) report that patients who present to the hospital for alcohol withdrawal have a high rate of readmission and experience significant morbidity and mortality. Patients with AWS may also have comorbidities that worsen their morbidity and mortality rates (Larson et al., 2012). Patients who have acute respiratory distress syndrome (ARDS) or septic shock are at increased risk for complications and multiple organ dysfunction (Larson et al., 2012). According to Larson et al. (2012), patients in the intensive care unit (ICU) who have alcohol dependence have higher morbidity, including septic shock, and higher hospital mortality. Larson et al. (2012) report that in-hospital mortality from AWS is high but with benzodiazepines, hospital mortality rates have decreased.

\section{Cost Due to AWS}


Alcohol withdrawal syndrome contributes a high burden to social costs (Soravia et al., 2018). Sachdeva et al. (2015) state that the choice of treatment setting has important cost implications. Inpatient treatment of AWS leads to a higher cost compared to outpatient treatment (Sachdeva et al., 2015). A higher cost with inpatient treatment occurs due to the occurrence of more severe symptoms (Sachdeva et al., 2015). When an individual experiencing AWS presents to a physician's office or emergency department, choice of treatment is made depending on the severity of withdrawal symptoms (Sachdeva et al., 2015). The experience of moderate to severe withdrawal symptoms in addition to a patient's comorbidities increases the amount of benzodiazepines given, which increases cost and the level of care required (Sachdeva et al., 2015).

\section{Clinical Institute Withdrawal Assessment (CIWA)}

The Clinical Institute Withdrawal Assessment for Alcohol-Revised Scale (CIWAAr) is a validated scale used to assess symptoms of alcohol withdrawal. There are a total of 10 symptoms assessed using the CIWA-Ar scale including nausea/vomiting, tremors, sweating, anxiety, agitation, headache, orientation, visual/auditory hallucinations, and tactile disturbances (Eberly et al., 2016). The maximum score on the CIWA-Ar is 67. Scores that are less than 10 indicate mild withdrawal, scores 10-18 indicates moderate to severe withdrawal, and scores greater than 18 can indicate the patient is at risk for complications if not treated (Perry, 2014). The CIWA-Ar is administered by a nurse, requires patient participation, and takes about two minutes to administer (Perry, 2014).

The nurse asks the patient questions about the CIWA symptoms including any presence of headache, anxiety, nausea, auditory/visual/tactile disturbances, and assesses the patient's orientation. The nurse objectively assesses whether the patient is experiencing 
vomiting, agitation, diaphoresis, and tremors. The CIWA-Ar scale is administered every eight hours if the patient is not experiencing any symptoms (Perry, 2014). If the patient is scoring between eight and ten, then hourly assessments should be completed (Perry, 2014).

\section{Evidence Based Treatments}

\section{Non-Pharmacologic Management}

Patients undergoing alcohol withdrawal should be in a quiet room with minimal stimulation and low lighting (Sachdeva et al., 2015). Alcohol consumption causes dehydration in individuals when withdrawing from alcohol; patients need to be encouraged to drink fluids orally. If the patients cannot consume enough liquids orally, then intravenous hydration would be considered (Sachdeva et al., 2015). While consuming alcohol, patient's nutritional status also declines. Balanced nutrition with adequate amounts of vitamins including folic acid, multivitamin, and thiamine are encouraged (Sachdeva et al., 2015).

\section{Pharmacologic Management}

Benzodiazepines are the first-line therapy for the treatment of alcohol withdrawal (Adis Medical Writers, 2014). Long-acting and short-acting benzodiazepines are used for treatment of AWS and both have advantages and disadvantages. Longer-acting benzodiazepines provide a smoother withdrawal due to its longer-lasting effects (Adis Medical Writers, 2014). Hepatic impairment and delirium in the elderly are two complications of long-acting benzodiazepines that are disadvantages (Adis Medical Writers, 2014). Short-acting benzodiazepines are preferred in the elderly and in individuals with hepatic impairment (Adis Medical Writers, 2014). Benzodiazepines are 
metabolized by the liver, which can cause increased hepatic impairment in individuals already compromised. Elderly patients have been shown to have a $50 \%$ decline in clearance of benzodiazepines and a two-fold increase in accumulation of their metabolites causing these patients to be at an increased risk of over-sedation with longacting benzodiazepines (Perry, 2014). Patients with hepatic impairment or liver disease, a common co-morbidity for those with high alcohol intake, also have a two-fold increase in metabolite accumulation (Perry, 2014). The short-acting benzodiazepines lorazepam and oxazepam are preferred in the elderly and patients with hepatic impairment to decrease the risk of over-sedation (Perry, 2014).

Benzodiazepines perform their pharmacologic action at the GABA receptors (Eberly et al., 2016). The binding of the medication to the GABA receptors causes an enhancement in the inhibitory action that is suppressed when drinking alcohol. This causes reduced excitability of the neurons, causing a decrease in the symptoms of AWS, most importantly a reduction in seizures and DTs (Eberly et al., 2016). The use of benzodiazepines comes with many side effects and risks. Some side effects include drowsiness, confusion, dizziness, blurred vision, weakness, slurred speech, lack of coordination, difficulty breathing, and coma when used in excessive amounts (Uzon et al., 2010). Chronic abuse of benzodiazepines, results in changes in relationships, appearance, behavior, mood, and school or work performance (Uzon et al., 2010). Other side effects of chronic abuse include insomnia, anxiety, anorexia, and headaches (Uzon et al., 2010). The biggest risks associated with benzodiazepines are they can lead to physical and psychological dependence (Uzon et al., 2010) or reliance on this substance. When the substance is removed, withdrawal symptoms can occur (Uzon et al., 2010). Because of 
these side effects and risk of dependence, the treatment of AWS should ensure that the lowest dose of benzodiazepines is given to treat the syndrome.

Three dosing strategies for the treatment of AWS with benzodiazepines are used in practice. These treatment modalities include front-loading, fixed dose, and symptomtriggered benzodiazepine dosing (Adis Medical Writers, 2014). According to Eberly et al. (2016), a lack of standardization for the treatment and monitoring of AWS is apparent. The different treatment modalities will be described further.

\section{Front Loading Dosing}

According to Adis Medical Writers (2014), front-loading dosing, also known as loading dose strategy, is the use of high doses of longer-acting benzodiazepines to achieve rapid initial sedation and a self-tapering effect over time as the drug and its metabolites are eliminated from the body. With this strategy, initial doses of very high doses of benzodiazepines such as diazepam and chlordiazepoxide, are given, and doses are repeated everyone to two hours until adequate sedation occurs (Adis Medical Writers, 2014). An average of three high doses are needed to achieve a level of sedation (Adis Medical Writers, 2014). With this treatment, intensive monitoring is required to prevent respiratory depression (Adis Medical Writers, 2014). According to Perry (2014), the benefit to front-load dosing is that the most intensive monitoring and intensive medication administration is in the early period of the treatment plan. Sachdeva et al. (2015) state that the withdrawal severity and the clinical condition need to be monitored before each dose of medication.

\section{Fixed-Schedule Dosing}


A fixed-dose regimen requires that a set amount of the benzodiazepine be administered at regular intervals without any regard to the patient's symptoms Adis Medical Writers, 2014). This strategy is helpful in patients who require medication despite having or not having withdrawal symptoms such as those with history of withdrawal seizures or delirium tremens (Adis Medical Writers, 2014). Perry (2014), states that patients should still be monitored using the CIWA while receiving fixedschedule dosing and should be treated for breakthrough symptoms. According to Perry (2014), these patients should also be monitored for symptoms of benzodiazepine toxicity.

According to Skinner (2014), fixed-schedule dosing is characterized by benzodiazepines being administered at scheduled dosing and then slowly tapered. Skinner (2014) states that fixed-dose scheduling may cause over-sedation and lead to unnecessary medication administration to patients who do not require treatment.

Sachdeva et al. (2014) states that initial doses are determined by presenting symptoms and the time of last alcohol consumption. According to Sachdeva et al. (2015), if a patient is admitted and a CIWA-Ar scale cannot be obtained accurately due to symptoms, then the fixed-dose scheduling should be used.

\section{Symptom-Triggered Dosing}

Adis Medical Writers (2014) states that symptom-triggered therapy is administered depending on the presence of withdrawal symptoms assessed using the CIWA-Ar scale. They further report that the duration of treatment with this method is short and the amount of total medication administered is lower than with the fixed-dose regimen. Cassidy et al. (2012) reports that symptom-triggered therapy for AWS can avoid both the under-treatment or the overtreatment of AWS with benzodiazepines. Cassidy et 
al. (2012) also states that this approach reduces cumulative benzodiazepine dosage and duration of treatment in the hospital.

According to Perry (2014), in order for this method to be successful, patients must be symptomatic and regular assessment of the patient's symptoms with the CIWA-Ar scale must be performed. Once the patients are stable, they can be reassessed every four to eight hours (Perry, 2014). According to Skinner (2014), in symptom-triggered therapy, benzodiazepines are administered in response to the development of AWS symptoms while the provider uses the CIWA-Ar or another monitoring tool to assess symptoms. The patients receiving this treatment only receive medications when they experience symptoms (Skinner, 2014).

Sachdeva et al. (2015) described the symptom-triggered therapy approach as giving scores using the CIWA-Ar at fixed schedules, but only giving medication when the symptoms rated on the scale warrant it. According to Sachdeva et al. (2015), symptom-triggered therapy is preferred over other methods because it results in the administration of less medication and shorter duration of treatment. This method may also decrease the risk of under medicating of over-medicating a patient (Sachdeva et al., 2015). Sachdeva et al. (2015) states that this method can be effective if assessments of patient's symptoms are valid and accurate.

Total Dosage of Benzodiazepines: Fixed Schedule Dosing versus Symptom-

\section{Triggered Therapy}

Eberly et al. (2016) performed a retrospective chart review in October 2014 with patients who received symptom-triggered therapy using the CIWA-Ar protocol. The purpose of the study was to monitor the average daily dose and cumulative dose of 
diazepam given during the hospital stay. Charts were reviewed of patients who had received at least one dose of diazepam during their stay. The pre-protocol group included patients who had received both diazepam tapers and symptom-based therapy using the CIWA-Ar. The post-protocol group included only patients who were receiving symptomtriggered therapy using the CIWA-Ar. A total of 174 patients were included in the study. The average daily dose of benzodiazepine was higher in the pre-protocol group (12.1 mg) compared to the average daily dose of the post-protocol group (5.2 $\mathrm{mg}$ ) (Eberly et al., 2016).

Taheri et al. (2014) also conducted a retrospective chart review in a tertiary care center in Vancouver, Canada. The purpose of the study was to evaluate whether the implementation of symptom-triggered therapy reduced the cumulative dose of benzodiazepines administered. Thirty-three participants were in the pre-protocol group and thirty were in the post-protocol group. The method of treatment in the pre-protocol group was using a fixed-dose schedule only. In the post-protocol group, patients only received symptom-triggered therapy. The median cumulative dose of benzodiazepines decreased from $9 \mathrm{mg}$ in the pre-protocol group to $3 \mathrm{mg}$ in the post-protocol group (Taheri et al., 2014). 


\section{Theoretical Framework}

The Middle-Range Theory of Unpleasant Symptoms was developed in 1995 by researchers who were also involved in clinical practice. The theory states that all symptoms are interrelated and share common causative factors (Lenz et al., 1997). Because it is believed that symptoms share common causative factors, there can be one theory that can guide research regarding an array of symptoms (Lenz et al., 1997). The Theory of Unpleasant Symptoms proposes that since multiple symptoms occur together in response to one single event, similar interventions may alleviate or treat these symptoms (Lenz et al., 1997). The theory was updated since its original development. The original version stated that unpleasant symptoms were unidirectional relationships and not interrelated. The current version of the theory depicts that these symptoms may be reciprocal (Lenz et al., 1997). Symptoms are of grave importance in health care, and they are the main focus of this theory.

The theory is described as being comprised of three components: the symptoms the individual is experiencing, the factors that influence the symptom experience, and the consequences of the symptoms (Lenz et al., 1997). Lenz et al. (1997) proposes if multiple symptoms occur together, they may exacerbate each other. All symptoms have common characteristics, which include intensity, timing, level of distress perceived, and quality. These characteristics are all separate, but related to one another (Lenz et al., 1997). Intensity describes the severity, strength, or amount of symptom experienced by the patient. Time characteristic includes frequency, duration, and timing of the symptom. The distress dimension is the degree of effect it has on a person or how badly a person is bothered by a symptom (Lenz et al., 1997). 
There are three categories identified in the Theory of Unpleasant Symptoms for influencing the intensity, timing, distress level, and quality of symptoms: physiological factors, psychological factors, and situational factors as illustrated in Appendix C. According to Lenz et al. (1997), these categories are also interrelated and may interact to influence symptoms. Physiological factors include normal body functions, pathology, trauma, and energy level (Lenz et al., 1997). Psychological components include mental state, reaction to illness, and degree of uncertainty of symptoms and their meaning (Lenz et al., 1997). Situational factors include social and physical environment, which are comprised of employment status, marital status, social support, access to health care, diet, and exercise (Lenz et al., 1997). These three factors are related to one another and interact with each other in their relation to symptoms (Lenz et al., 1997). The final component of the theory is performance, defined as the "outcome" or "effect" the symptoms has on the individual (Lenz et al., 1997).

In summary, the Theory of Unpleasant Symptoms states that the experience of unpleasant symptoms can change one's physiological, psychological, and situational status (Lenz et al., 1997). For example, the withdrawal symptoms seen in alcohol withdrawal can affect a person's mental state, medical well-being, and situational factors such as housing. The theory stresses that symptoms can occur together and, when they do, they can be in synchrony and have additive effects (Lenz et al., 1997). Withdrawal symptoms can begin with one or two symptoms and as the individual progresses from mild to moderate withdrawal, more symptoms occur and their synchrony causes an additive effect, worsening their vital signs and mental state. This theory stresses the importance of being attentive to symptoms and knowing which interventions are best to 
treat all symptoms. In the case of alcohol withdrawal, the intervention is the use of a benzodiazepine to reduce all symptoms associated with withdrawal. Reducing symptoms may in turn reduce addictive effects, potentially improving physical and mental states. 


\section{Method}

\section{Purpose}

The purpose of this project is to conduct a systematic review to determine if the use of symptom-triggered dosing compared to fixed-schedule dosing of benzodiazepines for the treatment of AWS decreases total dosage of benzodiazepines administered. The research question is: Does the use of symptom-triggered therapy for alcohol withdrawal decrease total dosage of benzodiazepines given compared to fixed-dosed scheduling therapy?

\section{Inclusion and Exclusion Criteria}

Inclusion criteria included inpatients, outpatients, and adults aged 18 and over, full-text articles, English language, RCTs, and studies that compared fixed and symptombased benzodiazepine therapy. Exclusion criteria included pediatric focused articles (younger than 18 years old) and those involving participants with mental illness. The dates of the studies ranged from 2011-2019.

\section{Search Strategy}

This systematic review was conducted using the databases CINAHL, Google Scholar, and Cochrane. The search terms used included alcohol withdrawal, alcohol abuse treatment, symptom-triggered therapy, and fixed-dosed therapy. The articles were chosen based on the abstracts and the inclusion and exclusion criteria.

The Preferred Reporting Items for Systematic Reviews and Meta-analyses (PRIMSA) was used for evaluating information of each RCT in this systematic review. The Preferred Reporting Items for Systematic Reviews and Meta-Analyses (PRISMA) is an evidence-based minimum set of items for reporting in systematic reviews and meta- 
analyses (Moher et al., 2009). This method focuses on reporting the findings from multiple randomized controlled trials (RCTs) and other types of research (Moher et al., 2009). The PRISMA method can evaluate the interventions outlined in certain research papers (Moher et al., 2009). A systematic review is a review of a research question by finding relevant literature and collecting and analyzing the data from that literature (Moher et al., 2009). The PRISMA method consists of a 27 -item checklist and a fourphase flow diaphragm. The flow diagram is illustrated in Appendix A and shows the flow of information through different stages of a systematic review. With the diagram, you can map out the number of articles identified, included and excluded, and the reasons for exclusions (Moher et al., 2009). The PRISMA checklist illustrated in Appendix B allows review of areas in accordance with a systematic review, which include title, abstract, methods, results, discussion, and findings (Moher et al., 2009).

\section{Data Collection and Synthesis}

The author reviewed a total of 10 papers and excluded 6 because they were not randomized controlled trials. Some of the articles also were not within a time frame of ten years as search criteria of 2010-2020 were the range used. The articles chosen ranged from 2011-2019. All studies also excluded patients with severe mental illness.

This author carefully reviewed the chosen RCTs, and pertinent information was extracted and organized into tables. Table 1 includes the purpose, setting, sample, and design method of the articles. Table 2 will include the withdrawal scale used, medications used, exclusion criteria, and any limitations of the studies. 
Table 1.

\begin{tabular}{|c|c|c|c|c|}
\hline Purpose & $\begin{array}{l}\text { Setting and Time } \\
\text { Frame }\end{array}$ & Sample & Design Method & Citation \\
\hline $\begin{array}{l}\text {-To compare 24- } \\
\text { hour symptom } \\
\text { triggered therapy } \\
\text { and fixed-schedule } \\
\text { therapy }\end{array}$ & $\begin{array}{l}\text { Addiction ward at a } \\
\text { psychiatric tertiary } \\
\text { teaching hospital } \\
-7 \text { days }\end{array}$ & $\begin{array}{l}80 \text { patients on } \\
\text { the addiction } \\
\text { ward at PSH } \\
\text { Institute of } \\
\text { Medical Science } \\
\text { and Research, a } \\
\text { tertiary teaching } \\
\text { medical college } \\
\text { hospital }\end{array}$ & $\begin{array}{l}\text { Randomized } \\
\text { control study }\end{array}$ & $\begin{array}{l}\text { Gopal, R., \& } \\
\text { Chennatte, S. S. } \\
\text { (2019). } \\
\text { Comparing 24- } \\
\text { hour symptom } \\
\text { triggered therapy } \\
\text { and fixed } \\
\text { schedule } \\
\text { treatment for } \\
\text { alcohol } \\
\text { withdrawal } \\
\text { symptoms-A } \\
\text { randomized } \\
\text { control } \\
\text { study. Asian } \\
\text { Journal of } \\
\text { Psychiatry, 48, } \\
\text { 101888-101888. }\end{array}$ \\
\hline $\begin{array}{l}\text {-Compare efficacy } \\
\text { of a benzodiazepine } \\
\text { loading versus a } \\
\text { symptom triggered } \\
\text { protocol in the } \\
\text { management of } \\
\text { alcohol withdrawal }\end{array}$ & $\begin{array}{l}\text { Stanford University } \\
\text { Medical Center and } \\
\text { Palo Alto Veterans } \\
\text { Affairs } \\
\text {-12 months }\end{array}$ & $\begin{array}{l}47 \text { patients } \\
\text { admitted to one } \\
\text { of two tertiary } \\
\text { medical centers }\end{array}$ & $\begin{array}{l}\text { Prospective, } \\
\text { randomized } \\
\text { controlled trial }\end{array}$ & $\begin{array}{l}\text { Maldonado, J. R., } \\
\text { Nguyen, L. H., } \\
\text { Schader, E. M., \& } \\
\text { Brooks III, J. O. } \\
\text { (2012). } \\
\text { Benzodiazepine } \\
\text { loading versus } \\
\text { symptom- } \\
\text { triggered } \\
\text { treatment of } \\
\text { alcohol } \\
\text { withdrawal: a } \\
\text { prospective, } \\
\text { randomized } \\
\text { clinical } \\
\text { trial. General } \\
\text { hospital } \\
\text { psychiatry, 34(6), } \\
\text { 611-617. }\end{array}$ \\
\hline
\end{tabular}




\begin{tabular}{|c|c|c|c|c|}
\hline $\begin{array}{l}\text { Comparing fixed } \\
\text { tapering dose } \\
\text { regimen versus } \\
\text { symptom-triggered } \\
\text { regimen of } \\
\text { lorazepam for } \\
\text { alcohol } \\
\text { detoxification }\end{array}$ & $\begin{array}{l}\text { Department of } \\
\text { Psychiatry and De- } \\
\text { addiction at Post } \\
\text { Graduate Institute } \\
\text { of Medical } \\
\text { Education and } \\
\text { Research, Dr. Ram } \\
\text { Manohar Lohia } \\
\text { Hospital } \\
-12 \text { months }\end{array}$ & 63 male patients & $\begin{array}{l}\text { Prospective, } \\
\text { randomized, } \\
\text { double blind } \\
\text { controlled trial }\end{array}$ & $\begin{array}{l}\text { Sachdeva, A., } \\
\text { Chandra, M., \& } \\
\text { Deshpande, S. N. } \\
\text { (2014). A } \\
\text { comparative } \\
\text { study of fixed } \\
\text { tapering dose } \\
\text { regimen versus } \\
\text { symptom- } \\
\text { triggered regimen } \\
\text { of lorazepam for } \\
\text { alcohol } \\
\text { detoxification. Al } \\
\text { cohol and } \\
\text { Alcoholism, 49(3) } \\
\text {, 287-291. }\end{array}$ \\
\hline $\begin{array}{l}\text { Symptom-triggered } \\
\text { versus fixed- } \\
\text { schedule treatment } \\
\text { in an outpatient } \\
\text { setting }\end{array}$ & $\begin{array}{l}\text { Outpatient clinics } \\
\text { in five Copenhagen } \\
\text { Hospitals } \\
-10 \text { days }\end{array}$ & 163 patients & $\begin{array}{l}\text { Randomized } \\
\text { Controlled Trial }\end{array}$ & $\begin{array}{l}\text { Elholm, B., } \\
\text { Larsen, K., } \\
\text { Hornnes, N., } \\
\text { Zierau, F., \& } \\
\text { Becker, U. } \\
\text { (2011). Alcohol } \\
\text { withdrawal } \\
\text { syndrome: } \\
\text { symptom- } \\
\text { triggered versus } \\
\text { fixed-schedule } \\
\text { treatment in an } \\
\text { outpatient } \\
\text { setting. Alcohol } \\
\text { and } \\
\text { alcoholism, 46(3), } \\
\text { 318-323. }\end{array}$ \\
\hline
\end{tabular}


Table 2.

\begin{tabular}{|c|c|c|c|c|}
\hline Citation & $\begin{array}{l}\text { Withdrawal } \\
\text { Scale Used and } \\
\text { any training } \\
\text { given? }\end{array}$ & $\begin{array}{l}\text { Drugs used for } \\
\text { treatment }\end{array}$ & $\begin{array}{l}\text { Exclusion } \\
\text { Criteria }\end{array}$ & Limitations \\
\hline $\begin{array}{l}\text { Gopal et al. } \\
(2019)\end{array}$ & $\begin{array}{l}\text { Clinical } \\
\text { Institute } \\
\text { Withdrawal } \\
\text { Scale (CIWA) } \\
\text {-staff were } \\
\text { given didactic } \\
\text { lecture and live } \\
\text { demonstration } \\
\text { on how to } \\
\text { administer } \\
\text { CIWA }\end{array}$ & $\begin{array}{l}5 \text { patients were } \\
\text { given lorazepam, } \\
1 \text { from the STT } \\
\text { group and } 4 \text { from } \\
\text { the FST group, the } \\
\text { rest were given } \\
\text { chlordiazepoxide } \\
\text { - patient was given } \\
\text { 20mg } \\
\text { chlordiazepoxide } \\
\text { orally or } \\
\text { lorazepam } 1 \mathrm{mg} \\
\text { orally if the } \\
\text { patient had liver } \\
\text { dysfunction }\end{array}$ & $\begin{array}{l}\text { Age }<16 \text { and } \\
>65 \\
\text { - excluded } \\
\text { patients with } \\
\text { severe mental } \\
\text { illness. }\end{array}$ & $\begin{array}{l}\text {-Not double } \\
\text { blind } \\
\text {-study } \\
\text { participants all } \\
\text { men } \\
\text { - } \\
\text { chlordiazepoxide } \\
\text { and lorazepam } \\
\text { are tapered } \\
\text { differently }\end{array}$ \\
\hline $\begin{array}{l}\text { Maldonado } \\
\text { et al. (2012) }\end{array}$ & $\begin{array}{l}\text { Clinical } \\
\text { Institute } \\
\text { Withdrawal } \\
\text { Scale (CIWA) } \\
\text {-training was } \\
\text { given to } \\
\text { medical } \\
\text { students by } \\
\text { their seniors }\end{array}$ & $\begin{array}{l}\text {-lorazepam and } \\
\text { diazepam } \\
\text { - STT group were } \\
\text { treated with } \\
\text { lorazepam and } \\
\text { patients in the FST } \\
\text { group were treated } \\
\text { with diazepam. } \\
\text { Lorazepam dosage } \\
\text { was converted to } \\
\text { diazepam } \\
\text { equivalents based } \\
\text { on the } \\
\text { equipotency } \\
\text { conversion of } 1 \\
\text { mg of lorazepam } \\
\text { to } 5 \text { mg of } \\
\text { diazepam. }\end{array}$ & $\begin{array}{l}\text {-pregnancy, } \\
\text { history of } \\
\text { dementia, abuse } \\
\text { of depressant } \\
\text { agents, acute } \\
\text { intoxication with } \\
\text { CNS agents, } \\
\text { severe hepatic } \\
\text { dysfunction } \\
\text { (INR }>2 \text { ) } \\
\text { - excluded } \\
\text { patients with } \\
\text { severe mental } \\
\text { illness. }\end{array}$ & $\begin{array}{l}\text {-study was not } \\
\text { blind } \\
\text {-small sample } \\
\text { size } \\
\text {-46 males and } 1 \\
\text { female }\end{array}$ \\
\hline $\begin{array}{l}\text { Sachdeva et } \\
\text { al. (2014) }\end{array}$ & $\begin{array}{l}\text { Clinical } \\
\text { Institute } \\
\text { Withdrawal } \\
\text { Scale (CIWA) } \\
\text {-no teaching } \\
\text { specified in } \\
\text { article }\end{array}$ & -lorazepam & $\begin{array}{l}\text {-EKG } \\
\text { abnormalities, } \\
\text { cirrhosis, } \\
\text { abnormal } \\
\text { laboratory data } \\
\text { - excluded } \\
\text { patients with }\end{array}$ & $\begin{array}{l}\text {-small sample } \\
\text { size } \\
\text {-only male } \\
\text { subjects }\end{array}$ \\
\hline
\end{tabular}




\begin{tabular}{|c|c|c|c|c|}
\hline & & & $\begin{array}{l}\text { severe mental } \\
\text { illness. }\end{array}$ & \\
\hline $\begin{array}{l}\text { Elholm et al. } \\
(2011)\end{array}$ & $\begin{array}{l}\text { Short Alcohol } \\
\text { Withdrawal } \\
\text { Scale (SAWS) } \\
\text {-patients were } \\
\text { taught how to } \\
\text { self-administer } \\
\text { SAWS }\end{array}$ & $\begin{array}{l}\text {-chlordiazepoxide } \\
\text { - In the FST } \\
\text { group, 200mg } \\
\text { chlordiazepoxide } \\
\text { was prescribed as } \\
\text { a starting dose for } \\
\text { patients scoring } \\
>12 \text { on SAWS and } \\
\text { the dose was } \\
\text { tapered daily by } \\
25 \mathrm{mg} \text {. For patients } \\
\text { scoring < } 12 \text { on } \\
\text { SAWS, the } \\
\text { starting dose was } \\
80 \mathrm{mg} \text { and it was } \\
\text { tapered daily by } \\
10 \text { mg }\end{array}$ & $\begin{array}{l}\text {-<18 years old, } \\
\text { patients treated } \\
\text { for AWS within } \\
\text { the last week, } \\
\text { history of } 3 \text { or } \\
\text { more attempts of } \\
\text { outpatient } \\
\text { detoxification } \\
\text { within the last } \\
\text { month, allergy to } \\
\text { chlordiazepoxide } \\
\text { or known drug } \\
\text { interaction, } \\
\text { severe } \\
\text { psychiatric } \\
\text { illness, suicidal } \\
\text { behavior, severe } \\
\text { cardiac or liver } \\
\text { disease, pregnant } \\
\text { and } \\
\text { breastfeeding } \\
\text { women } \\
\text { - excluded } \\
\text { patients with } \\
\text { severe mental } \\
\text { illness. }\end{array}$ & $\begin{array}{l}\text {-study was } \\
\text { outpatient } \\
\text {-patients scored } \\
\text { themselves using } \\
\text { SAWS }\end{array}$ \\
\hline
\end{tabular}

\section{Critical Appraisal Tool}

The Critical Appraisal Skills Programme (CASP) was used to critically appraise each RCT and to evaluate the outcomes and revelations of the RCTs. The Critical Appraisal Skills Programme (CASP) was developed in Oxford in 1993 by Dr. Amanda Burls as a formal methodology (Singh, 2013). The CASP includes many checklists, each with 10-12 questions, for any research study found. For this paper, the 11-question checklist will be used to appraise the RCTs. The checklists allow readers to critically appraise and screen out certain areas of a research study (Singh, 2013). The CASP 
checklists also allow a reader to identify the strength and weaknesses of a research article (Singh, 2013). The CASP checklist for systematic reviews will be used for this paper and is shown in Appendix D.

The CASP tool for systematic reviews consists of three sections with multiple questions in each section. Section A reviews whether the results of the study are valid. Six questions are used to help the author identify whether the results are valid or not. Section B focuses on the results of the study in general and helps to clearly identify what each article is concluding. Section $\mathrm{C}$ explores whether the results will help locally, meaning impacting the local population (Singh, 2013). This section focuses on how the results can be applied to practice (Singh, 2013).

\section{Cross Analysis}

All of the studies will be cross analyzed in order to compare the differences and similarities in the findings. Table 3 below was created to organize the differences and similarities. The purpose of the table is to be able to compare the differences in total dosage of benzodiazepines received in the symptom-triggered dosing group versus the fixed dose schedule dosing group. Table 3 also depicts whether any adverse events in any of the groups occurred.

\section{Table 3}

\begin{tabular}{|l|l|l|l|l|}
\hline Authors & $\begin{array}{l}\text { Symptom } \\
\text { Triggered Group } \\
\text { Total Mean } \\
\text { Dosage of } \\
\text { Benzodiazepines } \\
\text { Received }\end{array}$ & $\begin{array}{l}\text { Fixed Dosing } \\
\text { Group Total } \\
\text { Mean Dosage of } \\
\text { Benzodiazepines } \\
\text { Received }\end{array}$ & $\begin{array}{l}\text { Duration of } \\
\text { Treatment }\end{array}$ & Adverse Events \\
\hline $\begin{array}{l}\text { Gopal et al. } \\
(2019)\end{array}$ & $115 \mathrm{mg}$ & $210 \mathrm{mg}$ & $\begin{array}{l}\text { 120 hours in } \\
\text { STT group } \\
\text { and 144 hours } \\
\text { in FST Group }\end{array}$ & None noted \\
\hline
\end{tabular}




\begin{tabular}{|c|c|c|c|c|}
\hline $\begin{array}{l}\text { Maldonado et } \\
\text { al. (2012) }\end{array}$ & $92.4 \mathrm{mg}$ & $103.8 \mathrm{mg}$ & Not assessed & $\begin{array}{l}\text { Two patients in } \\
\text { each group } \\
\text { developed } \\
\text { treatment- } \\
\text { refractory } \\
\text { delirium } \\
\text { tremens. }\end{array}$ \\
\hline $\begin{array}{l}\text { Sachdeva et al. } \\
(2014)\end{array}$ & $9.5 \mathrm{mg}$ & $19.9 \mathrm{mg}$ & $\begin{array}{l}146 \text { hours in } \\
\text { FST group } \\
\text { compared to } \\
47.8 \text { hours in } \\
\text { STT group }\end{array}$ & $\begin{array}{l}4 \text { patients in the } \\
\text { FST group had } \\
4 \text { adverse } \\
\text { effects } \\
\text { (delirium, } \\
\text { hallucinations, } \\
\text { insomnia, and } \\
\text { increased } \\
\text { severity of } \\
\text { symptoms) } \\
\text { compared to } 6 \\
\text { patients in the } \\
\text { STT group }\end{array}$ \\
\hline $\begin{array}{l}\text { Elholm et al. } \\
(2011)\end{array}$ & $725 \mathrm{mg}$ & $875 \mathrm{mg}$ & $\begin{array}{l}\text {-all patients } \\
\text { treated for ten } \\
\text { days }\end{array}$ & None noted \\
\hline
\end{tabular}

\section{Summary of Tables}

After reviewing all of the RCTs, it is evident that they all share one common theme. That theme is that the use of symptom triggered therapy (STT) leads to a decreased total mean dosage of benzodiazepines administered during treatment for alcohol withdrawal compared to fixed schedule therapy (FST). No major differences were noted with adverse effects as only one study spoke about adverse effects noted in both groups. There were limitations to each study as noted above. Three of the randomized controlled trials were conducted in inpatient settings, and one was conducted in an outpatient setting. 


\section{Results}

Gopal et al. (2019) conducted a randomized control trial to compare the efficacy of two treatment strategies for AWS, symptom-triggered therapy (STT) and fixedschedule therapy (FST). The primary outcome of the study was to measure the total dose of benzodiazepine administered and the duration of detoxification in both treatment groups. This study took place in the de-addiction ward of PSG Institute of Medical Science and Research, a tertiary teaching medical college hospital. Study participants were between the ages of 16 and 65 who were admitted and met the DSM IV criteria for alcohol dependence. Written consent was obtained from all participants. This study was approved by the human ethics board of the institution. The patients were randomized using a computer-generated randomization technique into the two treatment strategy groups. All of the nurses on the de-addiction ward were trained on the use of the CIWAAr through didactic lecture followed by a live demonstration. The nurses were then shown a video showing an interview done on two patients while another nurse was conducting a CIWA-Ar.

In the symptom-triggered treatment group, a nurse on the ward performed a CIWA-Ar on the patients every hour and if the score was found to be below ten for three consecutive ratings, then the CIWA-Ar was performed every four hours. If the CIWA-Ar score was greater than or equal to ten, the patient was given $20 \mathrm{mg}$ of chlordiazepoxide orally or lorazepam 1mg orally if the patient had liver dysfunction (Gopal et al., 2019). In the fixed-schedule treatment group, when the patient was admitted to the de-addiction ward, the admitting physician decided the initial dose of benzodiazepine, lorazepam or 
chlordiazepoxide. Starting on the third day of admission, the dose of benzodiazepine would begin to be tapered daily.

During the course of treatment, an independent investigator who was blind to the treatment regimens administered CIWAs to patients in both treatment groups for seven days. A total of 80 patients were included in the study, 40 randomized into each treatment group. Eleven patients dropped out of the study because they were discharged before completion of their detoxification. Lorazepam was used for 5 patients and chlordiazepoxide was used for the remaining patients. All patients in the FST group received benzodiazepines while 28 patients $(70 \%)$ in the STT group received benzodiazepines. Twelve patients $(30 \%)$ in the STT group were determined to not need benzodiazepines based on symptom assessment.

The mean total dose of benzodiazepines administered to patients overall in both treatment groups was $95 \mathrm{mg}$ lower in the STT group than it was in the FST group. The total mean dosage amount of benzodiazepine in the STT group was $115 \mathrm{mg}$ and $210 \mathrm{mg}$ in the FST group. The duration of detoxification was significantly shorter in the STT group than in the FST group. In the STT group, the duration was 120 hours as compared to 144 hours in the FST group. According to the independent assessor, the CIWA-Ar scores were similar in both groups being on the low end of the scale, suggesting that withdrawal symptoms were well controlled. This finding shows that although the CIWAAr scores were similar, the patients in the FST group were given benzodiazepines when they did not need them.

According to Gopal et al. (2019), the biggest limitation to the study was it not being a double-blind study. Another limitation was that the tapering doses for 
chlordiazepoxide (10 mg per day) compared to lorazepam (1 mg per day). No patients suffered from adverse effects during the study, but there was no structured assessment for adverse effects, which was another limitation cited.

Maldonado et al. (2012) conducted an open, prospective, randomized clinical trial over a 12-month period to compare the efficacy of a benzodiazepine fixed-schedule dosing versus a symptom-triggered therapy in the treatment of AWS. The study was conducted at two tertiary care medical facilities, Stanford University Medical Center (SUMC) and the Palo Alto Veterans Affairs (PAVA). Patients who were admitted with alcohol withdrawal symptoms were included. Eligible patients included those with a history of alcohol withdrawal or dependence, age 18 or older, and anyone who consumed alcohol within 24 hours of admission. Exclusion criteria included pregnancy, history of dementia, reports of active abuse of CNS depressants, acute intoxication with CNSactivating agents, severe hepatic dysfunction, or unwillingness to participate in the study.

A total of 47 participants in the study were randomized into two groups, 23 subjects in the FST group and 24 subjects in the STT group. The CIWA-Ar scales were administered blindly three times a day by a nurse on the unit. Patients in the STT group were treated with lorazepam and patients in the FST group were treated with diazepam. Lorazepam dosage was converted to diazepam equivalents based on the equipotency conversion of $1 \mathrm{mg}$ of lorazepam to $5 \mathrm{mg}$ of diazepam. The total mean dosage of benzodiazepines administered in the FST group was $103.8 \mathrm{mg}$ and $92.4 \mathrm{mg}$ in the STT group. Length of stay was not calculated in this study. Two patients in each group developed treatment-refractory delirium tremens. No patients suffered from respiratory 
depression or seizures. Per Maldonado et al. (2019), limitations to this study included an unblinded design and a small sample size.

Sachdeva et al. (2014) also conducted a prospective, randomized, double blind controlled trial to compare fixed-schedule treatment versus symptom-triggered therapy for alcohol detoxification. The study took place in at Post Graduate Institute of Medical Education and Research, a free tertiary care de-addiction center in India. The study included 63 male participants who were admitted to the de-addiction unit for alcohol withdrawal. Lorazepam was the only benzodiazepine used in this study for all patients. The study was conducted between November 2010 and November 2011. All patients signed consent forms. Exclusion criteria included major Axis-I psychiatric disorders, severe medical illness (encephalopathy, delirium), dependence on other substances, mini mental status exam of less than 23 , and history of head injury or mental retardation. All patients were scored using the CIWA-Ar. All patients were randomized into a fixedschedule treatment group or a symptom-triggered treatment group.

The total mean dosage of benzodiazepines in the FST group was $19.9 \mathrm{mg}$ compared to $9.5 \mathrm{mg}$ in the STT group. Two patients in the STT group did not receive any benzodiazepines because they were noted to have mild withdrawal (CIWA-Ar less than 8). All patients in the FST group received benzodiazepines. The duration of treatment in the FST group was 146 hours compared to 47.8 hours in the STT group. Patients in the FST group received the drug for 80 hours more than the patients in the STT group. Patients continued to receive benzodiazepines even after three consecutive CIWA-Ar scores of less than 8. Four patients in the FST group suffered adverse events compared with five patients in the STR group. Adverse events were described as seizures, delirium, 
hallucinations, increased severity of withdrawal symptoms, and insomnia. One patient had a seizure in the FST group, and no patient had a seizure in the STT group. One patient in each group developed delirium. No patients suffered from over-sedation. Limitations to the study includes the decision to include only male subjects.

Another randomized controlled trial was conducted by Elhom et al. (2011) to investigate whether there are any advantages of treatment of alcohol withdrawal with a symptom triggered therapy approach versus a fixed-schedule treatment approach. This study was conducted on an outpatient basis at five Copenhagen hospitals. Exclusion criteria included patients who had been treated for AWS within the last week, history or three or more attempts of outpatient detoxification within the last month, allergy to chlordiazepoxide, severe psychiatric illness, suicidal behavior, severe cardiac or liver disease, type 1 diabetes, and pregnancy. Informed consent was obtained for all patients.

All patients were treated with chlordiazepoxide. One hundred and fifty-three patients were included in this study, and they were all randomized into either a FST or an STT group. In the FST group, 200mg chlordiazepoxide was prescribed as a starting dose for patients scoring $>12$ on SAWS, and the dose was tapered daily by $25 \mathrm{mg}$. For patients scoring $<12$ on SAWS, the starting dose was $80 \mathrm{mg}$, and it was tapered daily by $10 \mathrm{mg}$. All of the patients in the FST group were told to take the medication in fixed daily doses. In the STT group, patients scoring $>12$ on SAWS were prescribed a maximum daily dose of $300 \mathrm{mg}$ for 10 days. Patients scoring $<12$ on SAWS were prescribed a maximum daily dose of $120 \mathrm{mg}$ for 10 days. The patients in the STT group were taught to administer benzodiazepines to themselves according to their symptoms rated on the SAWS. Patients in both groups had to personally attend the outpatient clinic daily for 10 
days. The mean dose of chlordiazepoxide in the STT group was $725 \mathrm{mg}$ compared to $875 \mathrm{mg}$ in the FST group. Limitations include the fact that this study was done in an outpatient setting, and that patients had to score themselves using the SAWS and had to medicate themselves. 


\section{Summary and Conclusions}

Alcohol abuse is one of the most common substance abuse disorders in the United States (Maldonado et al., 2012). It is seen daily in inpatient and outpatient healthcare settings. A variety of treatment regimens exist for AWS. Within these treatment regimens, various drugs can be administered, but benzodiazepines are preferred due to their safety and efficacy (Maldonado et al., 2012). The most commonly used benzodiazepines are chlordiazepoxide, lorazepam, oxazepam, and diazepam (Maldonado et al., 2012). The two most commonly used regimens for the treatment of AWS are fixedschedule treatment (FST) and symptom-triggered treatment (STT). The choice of treatment regimen is generally decided by the provider depending on the severity of the patient's withdrawal symptoms based on the first CIWA-Ar completed.

This systematic review was conducted to determine if the use of symptomtriggered dosing compared to fixed-schedule dosing of benzodiazepines for the treatment of AWS decreases total dosage of benzodiazepines administered during the course of treatment. A total of four articles were used to conduct this systematic review. The PRISMA framework was used to guide the selection of articles. CASP was used to critically appraise each article included. The theoretical framework used was the MiddleRange Theory of Unpleasant Symptoms. Databases used included CINAHL, Google Scholar, and Cochrane.

After reviewing all four articles, the main finding was that the use of a symptomtriggered dosing regimen for the treatment of AWS led to a decreased dosage of benzodiazepines administered compared to the fixed-schedule dosing regimen. Although not specifically stated in the purpose, analysis of these studies also indicated that the use of symptom-triggered dosing lead to a shorter duration of treatment. No study found that 
the use of symptom-triggered dosing compared to fixed-schedule dosing lead to increased adverse effects. All studies did note limitations to their studies. Due to the small number of articles found that were published within the last ten years regarding this subject, it is clear more research is required. Overall, this systematic review found that the use of symptom-triggered dosing does in fact decrease the total dosage of benzodiazepines administered compared to fixed-schedule dosing. 


\section{Recommendations and Implications for Advanced Nursing Practice}

The results of this systematic review can be helpful and useful for advanced practice nurses (APRNs) in all practice settings including outpatient detoxification centers and inpatient units that admit patients for AWS. The use of a symptom-triggered dosing strategy can lead to reduction in unnecessary administration of benzodiazepines, decreased costs, decreased duration of therapy, and decreased use of hospital resources. Cost is an issue that many facilities face, so the use of this symptom-triggered dosing can lead to a decreased level of care due to the reduced amount of benzodiazepines administered requiring close monitoring and assessment. Some of the studies showed that the use of this regimen led to decreased duration of therapy, which can translate into a decreased length of stay. Decreased length of stay and duration of therapy also leads to effective utilization of resources which include drugs, personnel, hospital beds, and time (Sachdeva et al., 2014).

It is also important to remember that as APRNs, there is a responsibility to advocate for the patient. When admitting a patient with AWS, many aspects of the patient's history and assessment should be taken into consideration, for example the patients' blood alcohol level (BAL) and history of withdrawal. For patients with a history of a more "difficult" withdrawal, they should receive the fixed dosed scheduling regimen to ensure the patient is receiving consistent benzodiazepines and prevent withdrawal symptoms. When admitting a patient with who does not have a history of a difficult withdrawal including intubation and withdrawal seizures, then a symptom triggered regimen should be considered in efforts to medicate the patient according to their symptoms and prevent over sedation from over medication to the patient. Advocating to ensure the patient does not receive over treatment or under treatment for AWS also leads 
to an improved quality of life and better outcomes for the patient. Over sedating a patient can lead to the patient having a non-existential relationship with the health care team due to not being able to be part of the plan of care discussions. In contrary, if a patient does not receive adequate amounts of benzodiazepines, this can lead to adverse outcomes such as delirium tremens and intensive care unit (ICU) admission. This outcome would lead to poor family and patient communication, as well as poor communication with the health care team.

This leads to further discussion stating the need for a protocol development when caring for and admitting patients with AWS. There must be specific criteria in place in all health care settings to ensure advanced providers assess their patients adequately and choose a treatment regimen based on this assessment. Protocols and screening tools must be developed for universal use among all health care providers in all health care facilities. Once a protocol is in place, there must be education to ensure all providers including nursing personnel and advanced providers, are competent using the screening tools and following the protocols to safely and effectively care for a patient with alcohol withdrawal symptoms.

Advanced practice nurses everywhere should be aware of this body of research and their results. APRNs have the responsibility to ensure they provide the best care for their patients while also practicing in the best interest of their institution. APRNs have an important role in research and must always be looking for the best treatment options for their patients. Research efforts need to include any differences in treatment or response related to race, ethnicity, gender, and sex to assure health equity in treatment. Due to the 
limitations and limited randomized controlled trials done on this topic, further research must be done to expand this knowledge base. 


\section{References}

Adis Medical Writers dtp@ adis.com. (2014). Benzodiazepines are the mainstay of treatment for acute alcohol withdrawal syndrome. Drugs \& Therapy Perspectives, 30, 395-398.

Cassidy, E. M., O'Sullivan, I., Bradshaw, P., Islam, T., \& Onovo, C. (2012). Symptomtriggered benzodiazepine therapy for alcohol withdrawal syndrome in the emergency department: a comparison with the standard fixed dose benzodiazepine regimen. Emergency Medicine Journal, 29(10), 802-804.

Eberly, M. E., Lockwood, A. G., Lockwood, S., \& Davis, K. W. (2016). Outcomes implementation of an alcohol withdrawal protocol at a single institution. Hospital pharmacy, 51(9), 752-758

Elholm, B., Larsen, K., Hornnes, N., Zierau, F., \& Becker, U. (2011). Alcohol withdrawal syndrome: symptom-triggered versus fixed-schedule treatment in an outpatient setting. Alcohol and alcoholism, 46(3), 318-323.

Gopal, R., \& Chennatte, S. S. (2019). Comparing 24-hour symptom triggered therapy and fixed schedule treatment for alcohol withdrawal symptoms-A randomized control study. Asian Journal of Psychiatry, 48, 101888-101888.

Holbrook, A. M., Crowther, R., Lotter, A., Cheng, C., \& King, D. (1999). Meta-analysis of benzodiazepine use in the treatment of acute alcohol withdrawal. Cmaj, 160(5), $649-655$ 
Larson, S. A., Burton, M. C., Kashiwagi, D. T., Hugo, Z. P., Cha, S. S., \& Lapid, M. I. (2012). Multiple admissions for alcohol withdrawal. Journal of hospital medicine, $7(8), 617-621$.

Lenz, E. R., Pugh, L. C., Milligan, R. A., Gift, A., \& Suppe, F. (1997). The middle-range theory of unpleasant symptoms: an update. Advances in nursing science, 19(3), $14-27$.

Maldonado, J. R., Nguyen, L. H., Schader, E. M., \& Brooks III, J. O. (2012). Benzodiazepine loading versus symptom-triggered treatment of alcohol withdrawal: a prospective, randomized clinical trial. General hospital psychiatry, 34(6), 611-617.

Moher, D., Liberati, A., Tetzlaff, J., \& Altman, D. G. (2009). Preferred reporting items for systematic reviews and meta-analyses: the PRISMA statement. Annals of internal medicine, 151(4), 264-269.

Murdoch, J., \& Marsden, J. (2014). A 'symptom-triggered 'approach to alcohol withdrawal management. British journal of nursing, 23(4), 198-202.

National Institute on Alcohol Abuse and Alcoholism [NIAAA], 2019 https://www.niaaa.nih.gov/publications/brochures-and-fact-sheets/alcohol-factsand-statistics

Perry, E. C. (2014). Inpatient management of acute alcohol withdrawal syndrome. CNS drugs, 28(5), 401-410. 
Sachdeva, A., Choudhary, M., \& Chandra, M. (2015). Alcohol withdrawal syndrome: Benzodiazepines and beyond. Journal of clinical and diagnostic research.

Sachdeva, A., Chandra, M., \& Deshpande, S. N. (2014). A comparative study of fixed tapering dose regimen versus symptom-triggered regimen of lorazepam for alcohol detoxification. Alcohol and Alcoholism, 49(3), 287-291.

Schaffer, M. A., Sandau, K. E., \& Diedrick, L. (2013). Evidence-based practice models for organizational change: overview and practical applications. Journal Advanced Nursing, 69(5), 1197-1209.

Skinner, R. T. (2014). Symptom-triggered vs. fixed-dosing management of alcohol withdrawal syndrome. Medsurg Nursing, 23(5), 307.

Singh, J. (2013). Critical Appraisal Skills Programme. Journal of Pharmacology and Pharmacotherapeutics, 4(1), 76-77.

Soravia, L. M., Wopfner, A., Pfiffner, L., Bétrisey, S., \& Moggi, F. (2018). Symptomtriggered detoxification using the alcohol-withdrawal-scale reduces risks and healthcare costs. Alcohol and alcoholism, 53(1), 71-77.

Taheri, A., Dahri, K., Chan, P., Shaw, M., Aulakh, A., \& Tashakkor, A. (2014). Evaluation of a Symptom-Triggered Protocol Approach to the Management of Alcohol Withdrawal Syndrome in Older Adults. Journal of the American Geriatrics Society, 62(8), 1551-1555.

Uzun, S., Kozumplik, O., Jakovljević, M., \& Sedić, B. (2010). Side effects of treatment with benzodiazepines. Psychiatria Danubina, 22(1), 90-93 


\section{Appendix A}

\section{PRISMA 2009 Flow Diagram}
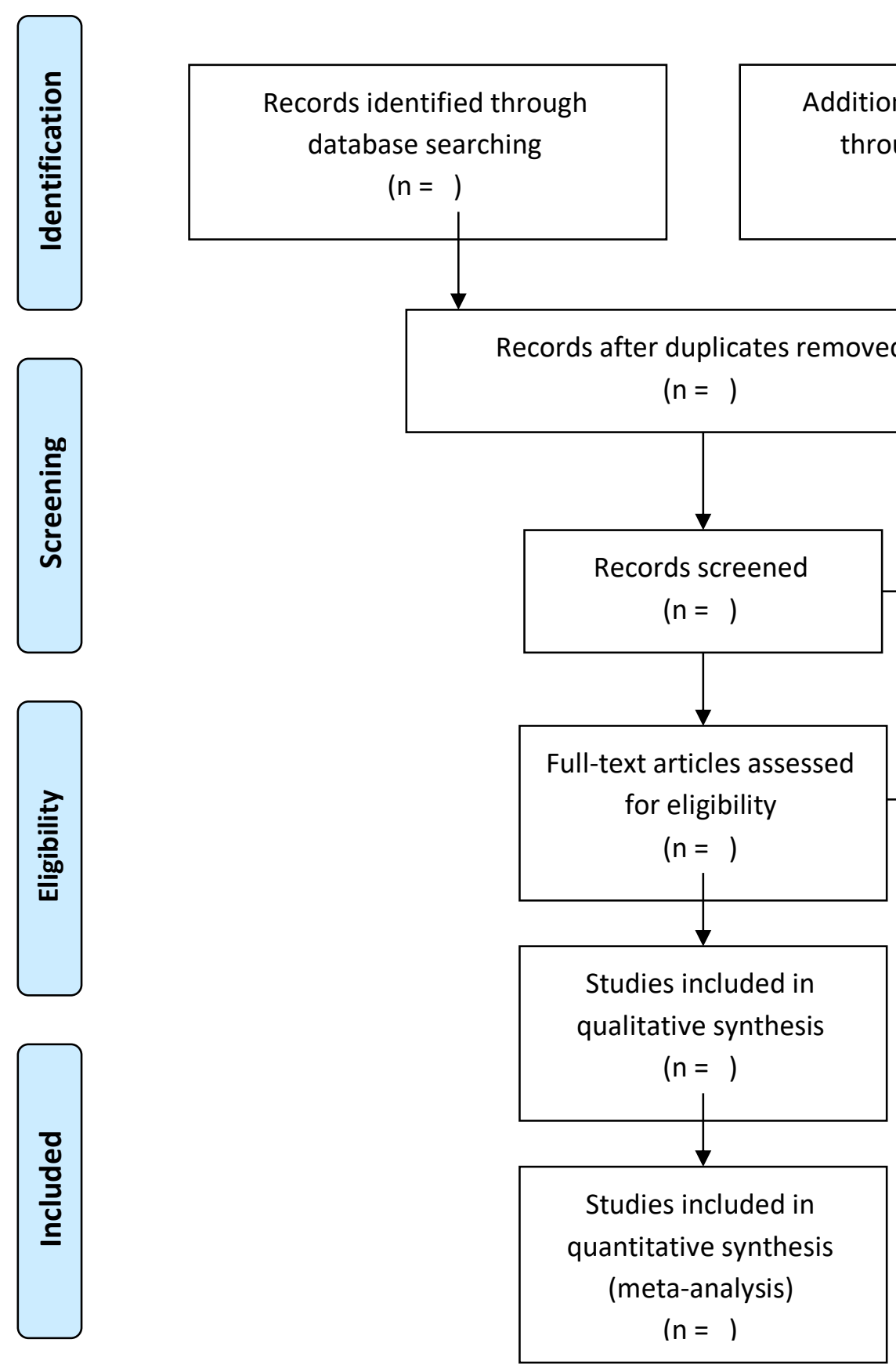

Records excluded $(n=)$ Full-text articles excluded, with reasons

$$
(n=)
$$




\section{Appendix B}

\section{PRISMA 2009 Checklist}

\begin{tabular}{|c|c|c|c|}
\hline Section/topic & \# & Checklist item & $\begin{array}{l}\text { Reported } \\
\text { on page \# }\end{array}$ \\
\hline \multicolumn{4}{|l|}{ TITLE } \\
\hline Title & 1 & Identify the report as a systematic review, meta-analysis, or both. & \\
\hline \multicolumn{4}{|l|}{ ABSTRACT } \\
\hline Structured summary & 2 & $\begin{array}{l}\text { Provide a structured summary including, as applicable: background; objectives; data sources; study eligibility criteria, } \\
\text { participants, and interventions; study appraisal and synthesis methods; results; limitations; conclusions and } \\
\text { implications of key findings; systematic review registration number. }\end{array}$ & \\
\hline \multicolumn{4}{|l|}{ INTRODUCTION } \\
\hline Rationale & 3 & Describe the rationale for the review in the context of what is already known. & \\
\hline Objectives & 4 & $\begin{array}{l}\text { Provide an explicit statement of questions being addressed with reference to participants, interventions, comparisons, } \\
\text { outcomes, and study design (PICOS). }\end{array}$ & \\
\hline \multicolumn{4}{|l|}{ METHODS } \\
\hline Protocol and registration & 5 & $\begin{array}{l}\text { Indicate if a review protocol exists, if and where it can be accessed (e.g., Web address), and, if available, provide } \\
\text { registration information including registration number. }\end{array}$ & \\
\hline Eligibility criteria & 6 & $\begin{array}{l}\text { Specify study characteristics (e.g., PICOS, length of follow-up) and report characteristics (e.g., years considered, } \\
\text { language, publication status) used as criteria for eligibility, giving rationale. }\end{array}$ & \\
\hline Information sources & 7 & $\begin{array}{l}\text { Describe all information sources (e.g., databases with dates of coverage, contact with study authors to identify } \\
\text { additional studies) in the search and date last searched. }\end{array}$ & \\
\hline Search & 8 & $\begin{array}{l}\text { Present full electronic search strategy for at least one database, including any limits used, such that it could be } \\
\text { repeated. }\end{array}$ & \\
\hline Study selection & 9 & $\begin{array}{l}\text { State the process for selecting studies (i.e., screening, eligibility, included in systematic review, and, if applicable, } \\
\text { included in the meta-analysis). }\end{array}$ & \\
\hline Data collection process & 10 & $\begin{array}{l}\text { Describe method of data extraction from reports (e.g., piloted forms, independently, in duplicate) and any processes } \\
\text { for obtaining and confirming data from investigators. }\end{array}$ & \\
\hline Data items & 11 & $\begin{array}{l}\text { List and define all variables for which data were sought (e.g., PICOS, funding sources) and any assumptions and } \\
\text { simplifications made. }\end{array}$ & \\
\hline $\begin{array}{l}\text { Risk of bias in individual } \\
\text { studies }\end{array}$ & 12 & $\begin{array}{l}\text { Describe methods used for assessing risk of bias of individual studies (including specification of whether this was } \\
\text { done at the study or outcome level), and how this information is to be used in any data synthesis. }\end{array}$ & \\
\hline Summary measures & 13 & State the principal summary measures (e.g., risk ratio, difference in means). & \\
\hline Synthesis of results & 14 & $\begin{array}{l}\text { Describe the methods of handling data and combining results of studies, if done, including measures of consistency } \\
\left(\mathrm{e} . \mathrm{g} ., \mathrm{I}^{2}\right) \text { for each meta-analysis. }\end{array}$ & \\
\hline
\end{tabular}

Page 1 of 2

\begin{tabular}{|c|c|c|c|}
\hline Section/topic & $\#$ & Checklist item & $\begin{array}{l}\text { Reported } \\
\text { on page \# }\end{array}$ \\
\hline Risk of bias across studies & 15 & $\begin{array}{l}\text { Specify any assessment of risk of bias that may affect the cumulative evidence (e.g., publication bias, selective } \\
\text { reporting within studies). }\end{array}$ & \\
\hline Additional analyses & 16 & $\begin{array}{l}\text { Describe methods of additional analyses (e.g., sensitivity or subgroup analyses, meta-regression), if done, indicating } \\
\text { which were pre-specified. }\end{array}$ & \\
\hline \multicolumn{4}{|l|}{ RESULTS } \\
\hline Study selection & 17 & $\begin{array}{l}\text { Give numbers of studies screened, assessed for eligibility, and included in the review, with reasons for exclusions at } \\
\text { each stage, ideally with a flow diagram. }\end{array}$ & \\
\hline Study characteristics & 18 & $\begin{array}{l}\text { For each study, present characteristics for which data were extracted (e.g., study size, PICOS, follow-up period) and } \\
\text { provide the citations. }\end{array}$ & \\
\hline Risk of bias within studies & 19 & Present data on risk of bias of each study and, if available, any outcome level assessment (see item 12). & \\
\hline Results of individual studies & 20 & $\begin{array}{l}\text { For all outcomes considered (benefits or harms), present, for each study: (a) simple summary data for each } \\
\text { intervention group (b) effect estimates and confidence intervals, ideally with a forest plot. }\end{array}$ & \\
\hline Synthesis of results & 21 & Present results of each meta-analysis done, including confidence intervals and measures of consistency. & \\
\hline Risk of bias across studies & 22 & Present results of any assessment of risk of bias across studies (see Item 15). & \\
\hline Additional analysis & 23 & Give results of additional analyses, if done (e.g., sensitivity or subgroup analyses, meta-regression [see ltem 16]). & \\
\hline \multicolumn{4}{|l|}{ DISCUSSION } \\
\hline Summary of evidence & 24 & $\begin{array}{l}\text { Summarize the main findings including the strength of evidence for each main outcome; consider their relevance to } \\
\text { key groups (e.g., healthcare providers, users, and policy makers). }\end{array}$ & \\
\hline Limitations & 25 & $\begin{array}{l}\text { Discuss limitations at study and outcome level (e.g., risk of bias), and at review-level (e.g., incomplete retrieval of } \\
\text { identified research, reporting bias). }\end{array}$ & \\
\hline Conclusions & 26 & Provide a general interpretation of the results in the context of other evidence, and implications for future research. & \\
\hline \multicolumn{4}{|l|}{ FUNDING } \\
\hline Funding & 27 & $\begin{array}{l}\text { Describe sources of funding for the systematic review and other support (e.g., supply of data); role of funders for the } \\
\text { systematic review. }\end{array}$ & \\
\hline
\end{tabular}

From: Moher D, Liberati A, Tetzlaff J, Altman DG, The PRISMA Group (2009). Preferred Reporting Items for Systematic Reviews and Meta-Analyses: The PRISMA Statement. PLoS Med 6(7): e1000097.

(PRISMA Transparent Reporting of Systematic Reviews and Meta-Analyses, 2015) 


\section{Appendix C}

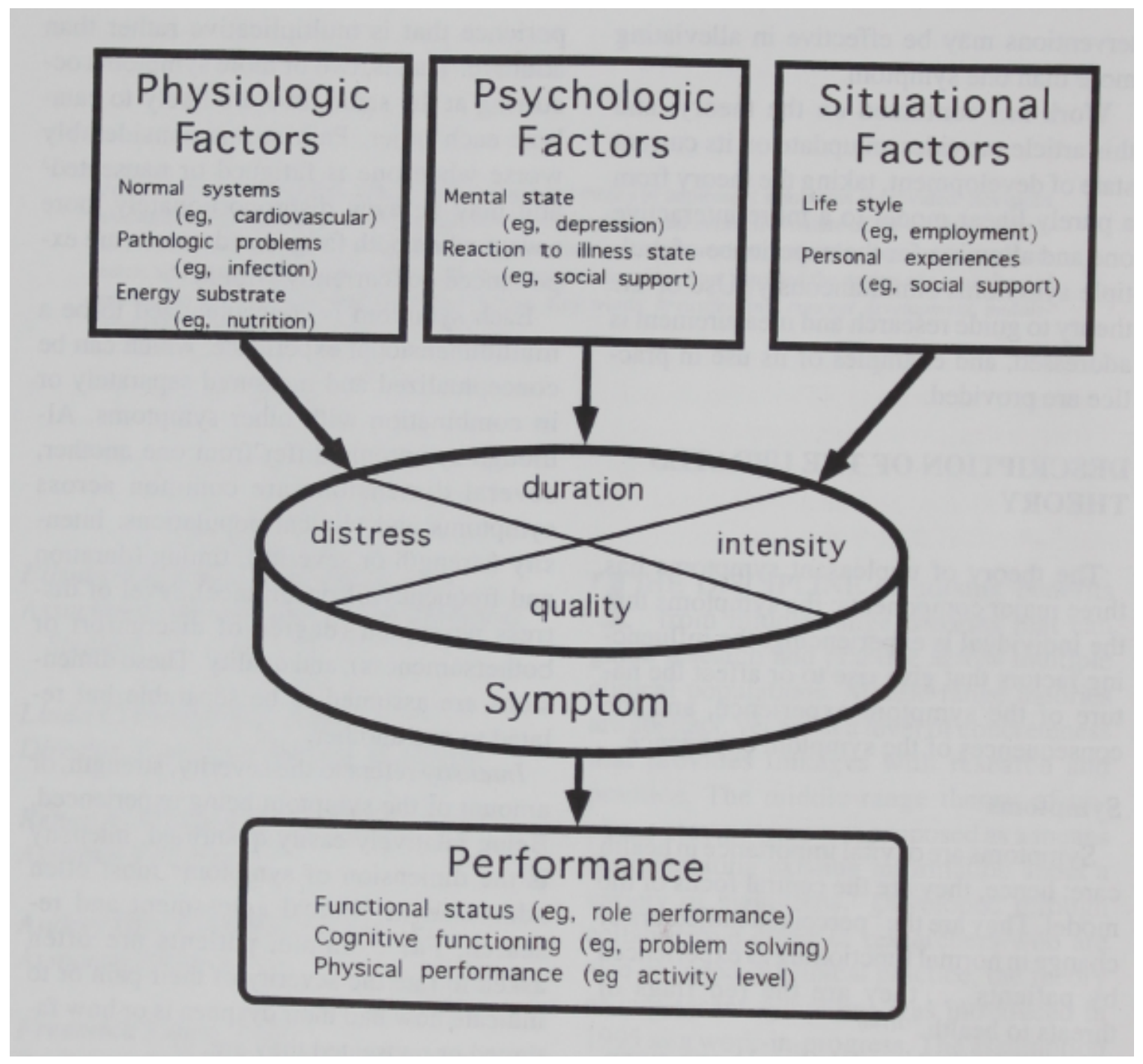

Lenz, E. R., Pugh, L. C., Milligan, R. A., Gift, A., \& Suppe, F. (1997). The middle-range theory of unpleasant symptoms: an update. Advances in nursing science, 19(3), 14-27. 


\section{Appendix D}

Section A: Are the results of the review valid?

1. Did the review address a clearly focused question?

2. Did the authors look for the right type of papers?

3. Do you think all the important, relevant studies were included?

4. Did the review's authors do enough to assess quality of the included studies?

5. If the results of the review have been combined, was it reasonable to do so?

Section B: What are the results?

6. What are the overall results of the review? Comment:

7. How precise are the results? Comment:

Section C: Will the results help locally?

8. Can the results be applied to the local population?

9. Were all important outcomes considered?

10. Are the benefits worth the harm and the costs?

\begin{tabular}{|l|l|l|}
\hline Yes & No & Can't Tell \\
\hline & & \\
& & \\
& & \\
& & \\
& & \\
\end{tabular}

